\title{
REVIEW
}

\section{Peroxisome proliferator-activated receptor gamma agonists in renal disease}

Pedro Iglesias and Juan J Díez ${ }^{1}$

Department of Endocrinology, Hospital General, Segovia, Spain and ${ }^{1}$ Hospital Ramón y Cajal, Madrid, Spain

(Correspondence should be addressed to P Iglesias; Email: piglesias@hgse.sacyl.es)

\begin{abstract}
Type 2 diabetes is a well recognised cause of chronic renal failure (CRF). Only few oral antidiabetic drugs can be used for treating type 2 diabetes in patients with CRF. Among them are repaglinide, a rapid-acting prandial insulin releaser, and peroxisome proliferator-activated receptor gamma $(\operatorname{PPAR} \gamma)$ agonists, such as rosiglitazone and pioglitazone. These compounds are metabolised in the liver, therefore accumulation of the drug and the risk of severe and prolonged hypoglycaemia are minimised. PPAR $\gamma$ receptors are expressed in many tissues including the kidney. Recently, numerous healthful effects of PPAR $\gamma$ agonists on several aspects related to renal function have been increasingly reported. These drugs have shown to possess many advantageous anti-inflammatory, haemodynamic, vascular and metabolic effects. In the present paper we have reviewed the more recent experimental studies that evaluated these potential beneficial effects of PPAR $\gamma$ agonists on renal function and revised the results of their utilisation in patients with different degrees of renal impairment, in dialysis patients, and in patients with diabetes mellitus after kidney transplantation. Finally, tolerability and safety profile of PPAR $\gamma$ agonists in patients with reduced glomerular filtration rate are also analysed.
\end{abstract}

European Journal of Endocrinology 154 613-621

\section{Introduction}

Diabetes mellitus is the leading cause of end stage renal disease (ESRD) (1). It has been demonstrated that exhaustive glycaemic control is associated with a decrease in the development and progression of diabetic nephropathy both in type 1 and type 2 diabetic patients $(2,3)$. Numerous drugs with different mechanisms of action are being used with the aim of improving glycaemic control. The use of these agents in both monotherapy and in combined therapy contribute to the reduction of glycosylated haemoglobin (HbAlc) concentrations and, consequently, of glomerular hyperfiltration and urinary albumin excretion (UAE) $(3,4)$.

Multiple drugs with different pharmacological profiles are employed in the management of type 2 diabetes (Table 1). Insulin secretagogues (sulphonylureas (SU) and rapid-acting prandial insulin releasers, meglitinides), biguanides (metformin), $\alpha$-glucosidase inhibitors and insulin have been used for many years with proven efficacy and safety $(5,6)$. The more recently introduced drugs include the peroxisome proliferator-activated receptor gamma (PPAR $\gamma$ ) agonists (thiazolidinediones or glitazones), the synthetic amylin analogues (pramlintide), the incretin mimetics as glucagon-like peptide-1 (GLP-1) analogues (exenatide and liraglutide) and the inhibitors of the incretin-degrading enzyme dipeptidyl peptidase-IV (vildagliptine, LAF-237 and sitagliptine, MK-0431) (5-9).

Therapeutic alternatives in patients with type 2 diabetes and ERSD are limited because of reduced glomerular filtration rate (GFR) is accompanied by accumulation of some drugs and/or their metabolites (10). PPAR $\gamma$ agonists are a new group of oral antidiabetic agents recently introduced in the therapy of type 2 diabetes $(6,11)$. These drugs are insulin sensitisers that reduce insulin resistance, increase glucose uptake in muscle and adipose tissue and, decrease hepatic glucose production (12). These antidiabetic oral agents are interesting in the clinical management of patients with type 2 diabetes and ESRD due to the fact that they are primarily metabolised at hepatic level, and therefore they do not accumulate in chronic renal failure (CRF). Moreover, these compounds might improve the uraemia-associated insulin resistance, and it has been shown that these agents give rise to some benefits on several aspects at the metabolic, inflammatory, vascular and haemodynamic levels. In this article we review the more recent aspects related to clinical efficacy and 
Table 1 Pharmacological therapy in type 2 diabetes mellitus.

\begin{tabular}{l}
\hline Oral agents \\
1) Insulin secretagogues \\
Sulphonylureas \\
First-generation: tolbutamide, acetohexamide, and \\
chlorpropamide \\
Second-generation: glyburide, glipizide, gliclazide, and \\
glimepiride \\
Meglitinides \\
$\quad$ Repaglinide \\
Nateglinide \\
2) Biguanides \\
Metformin \\
3) $\alpha$-Glucosidase inhibitors \\
Acarbose \\
Miglitol \\
4) PPARy agonists (glitazones or thiazolidinediones) \\
Pioglitazone \\
Rosiglitazone \\
5) Dipeptidyl peptidase-IV inhibitors \\
Vildagliptine (LAF-237) \\
Sitagliptine (MK-0431) \\
Parenteral agents \\
1) Insulin \\
2) Insulin analogues \\
Short-acting \\
Lyspro \\
Aspart \\
Glulisine \\
Long-acting \\
Glargine \\
Detemir \\
3) Amylin analogues \\
Pramlintide \\
4) Incretin mimetics: glucagon-like peptide-1 (GLP-1) \\
Exenatide \\
Liraglutide \\
\end{tabular}

safety profile of this new group of oral antidiabetic agents in patients with several renal conditions such as diabetic nephropathy, CRF on conservative management or dialysis therapy, and finally, post-transplant diabetes mellitus.

\section{PPAR receptors and PPAR agonists}

PPAR receptors are members of the steroid hormone nuclear receptor family. They belong to nuclear hormone superfamily of ligand-dependent transcription factors expressed in many tissues of the body including the kidney (13). In 1990, it was identified as the first PPAR receptor, now designated PPAR $\alpha$ (14). Two years later two additional isoforms of PPAR were identified, PPAR $\beta / \delta$ and PPAR $\gamma(15)$. Among PPAR ligands are hypolipidaemic drugs as fibrates (PPAR $\alpha$ agonists) and insulin sensitisers agents as thiazolidinediones or glitazones (PPAR $\gamma$ agonists). Whereas the former activate genes related to lipid metabolism, the latter produce several biological effects on adipogenesis, carbohydrate and lipid metabolism, inflammation processes, and cellular proliferation (13). Although both glitazones are basically PPAR $\gamma$ agonists, pioglitazone has a slight PPAR $\alpha$ agonistic property. Newer dualacting PPAR $\alpha$ and PPAR $\gamma$ agonists (glitazars) such as muraglitazar, ragaglitazar and tesaglitazar are currently being evaluated (16-18).

The interaction between PPAR agonists and their receptors at nuclear level allow the formation of a complex with another nuclear receptor known as retinoid X receptor (RXR), which is bound with its own ligand, retinoic acid (19). This heterodimeric complex results in a conformational change of these receptors, allowing the PPAR:RXR to recognise specific DNA response elements (PPAR response elements, PPRE) in the promoter region of target genes modulating gene transcription. This complex can turn on or turn off the expression of different genes involved in different metabolic pathways. Anti-inflammatory actions of PPAR receptors might be explained by other mechanisms interfering with other transcription-factor pathways in a DNA-independent way (20).

The antidiabetic effect of PPAR $\gamma$ agonists is based essentially in the reduction of insulin resistance at adipose tissue level after decreasing circulating free fatty acids through an increase of their cellular uptake and triglyceride synthesis, and in the promotion of the differentiation of pre-adipocytes. Glitazones increase glucose utilisation in muscle after activating gene expression of glucose transporter-4 (GLUT-4). These drugs also decrease both hepatic gluconeogenesis and the secretion and activity of the adipocyte-derived cytokine tumour necrosis factor- $\alpha$ (TNF- $\alpha$ ), a cytokine implicated in the development of impaired insulin action in muscle (6, 12). Other biologically promising effects of these drugs are related to other components of the metabolic syndrome such as hypertension, inflammation, and vascular dysfunction. Helpful actions on endothelial function have been reported. These effects include an increment of nitric oxide (NO) expression, vascular remodelling after reducing the progression of intima-media thickness associated with atherosclerosis and, finally, on microvascular effects $(5,12)$.

Both rosiglitazone and pioglitazone have similar glucose-lowering effects, decreasing $\mathrm{HbAlc}$ levels by around $0.5-1.5 \%(21-24)$. These drugs also exhibit some beneficial effects on lipid profile. While pioglitazone increases HDL-cholesterol and reduces triglycerides, rosiglitazone only elevates HDL-cholesterol levels. Moreover, rosiglitazone increases total cholesterol and LDL-cholesterol. Either drug reduces the proportion of the smaller and more dense LDL particles, with more atherogenic properties, increasing that of bigger and lower dense particles (12). A favourable effect of pioglitazone on secondary prevention of macrovascular events in patients with type 2 diabetes has been recently reported (25). However, in relation to newer dual PPAR $\alpha / \gamma$ agonists, it has been recently reported that muraglitazar, compared with placebo or pioglitazone, was associated with an excess incidence of the 
composite end point of death, major adverse cardiovascular events and congestive heart failure in patients with type 2 diabetes (18).

Rosiglitazone and pioglitazone have been approved for use in type 2 diabetes both in monotherapy and combined therapy. In the United States (US) these drugs are available for therapy in obese and non-obese patients with type 2 diabetes in which non-pharmacological measures have not been successful. In Europe they can be used in monotherapy only when metformin is not tolerated or is contraindicated, as it occurs in CRF. In combined therapy, in US, glitazones can be associated with other oral antidiabetic agents and insulin, while in Europe it is allowed only in association with SU or metformin (6).

\section{Metabolism of PPAR $\gamma$ agonists}

Pharmacokinetic profiles of PPAR $\gamma$ agonists makes these drugs potentially suitable for their use in patients with type 2 diabetes and CRF. Furthermore, the two available glitazones have an adequate oral bioavailability and are extensively metabolised by the liver. Rosiglitazone is mainly metabolised by cytochrome P450 (CYP) 2C8 into inactive metabolites. Less than $1 \%$ of the parent drug appears in the urine in unchanged form $(6,26)$. Both total and unbound plasma concentrations of rosiglitazone after a single 8-mg oral dose were not affected by the presence of mild, moderate, and severe renal insufficiency, thus indicating that the starting dose of rosiglitazone need not be adjusted in patients with renal impairment (27). Moreover, similar values of area under the concentration-time curve, maximum observed plasma concentrations, and half-life were observed in a group of 10 haemodialysis (HD) patients (non-dialysis day) in comparison with a group of healthy individuals after a single $8 \mathrm{mg}$ oral dose of rosiglitazone. These parameters were not markedly influenced by HD (28).

Metabolites of pioglitazone are more active and are excreted predominantly in the bile. Both pioglitazone as its metabolites M-III and M-IV do not accumulate in CRF. Pharmacokinetic profile of pioglitazone was similar in healthy subjects and in patients with moderate and severe renal failure (29).

\section{Possible nephroprotective actions of PPAR $\gamma$ agonists}

PPAR receptors are expressed in several tissues including the kidney $(13,30-32)$. PPAR $\alpha$ is predominantly expressed in proximal tubules and medullary thick ascending limbs, PPAR $\beta / \delta$ is equally expressed in renal cortex and medulla, while PPAR $\gamma$ is selectively expressed in medullary collecting ducts, glomeruli and pelvic urothelium (13). Through PPAR activation, PPAR $\gamma$ agonists exert some beneficial effects on the kidney, although the exact mechanism is not well understood. It is also unknown whether this protecting effect is due to a direct action on PPAR $\gamma$ at the glomerular, tubular and/or vascular level (33). Main protecting mechanisms at kidney level are summarised in Table 2 .

Some of the nephroprotective actions of glitazones take place at haemodynamic level. PPAR $\gamma$ agonists reduced blood pressure in obese, diabetic, and hypertensive rats $(34-38)$. Some authors have found a vasodilator effect of troglitazone, a PPAR $\gamma$ agonist, on the postglomerular efferent arteriole in rats (39). This drug has been shown to reduce blood pressure in type 2 diabetic patients (40). Moreover, rosiglitazone and pioglitazone reduced blood pressure in both hypertensive and non-hypertensive type 2 diabetic patients (41-45). Experiments in rats have demonstrated an increment in the NO production induced by PPAR $\gamma$ ligands after stimulating the expression of dimethylarginine dimethylaminohydrolase-II expression, an enzyme that degrades asymmetric dimethylarginine, one of the endogenous NO synthase (NOS) inhibitor (46). Multiple mechanisms on PPAR $\gamma$-induced haemodynamic effects have been suggested $(13,47)$. Among them are: (1) reduction in insulin resistance, which has been found to be associated with lower blood pressure in humans $(42,43,48)$, (2) direct vasodilator effects of PPAR $\gamma$ agonists, whose receptors have been found in both endothelium and vascular smooth muscle $(49,50)$, (3) modulation of release of vasodilator substances such as prostaglandins and NO $(46,51)$,

Table 2 Actions of glitazones potentially protecting kidney function.

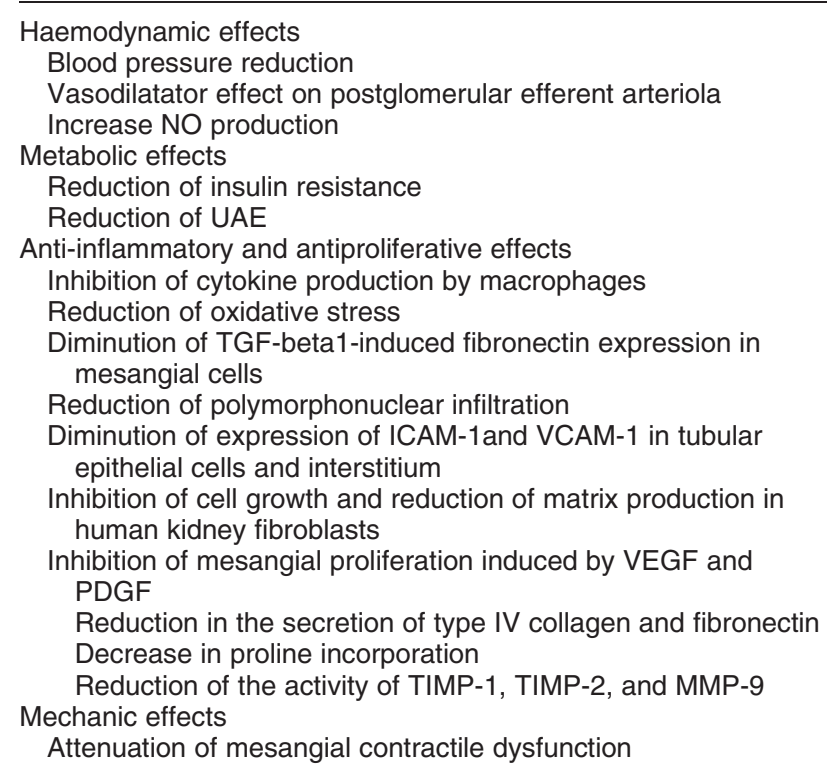

Abbreviations: NO, nitric oxide; UAE, urinary albumin excretion; TGFbeta1, transforming growth factor-beta1; ICAM-1, intercellular adhesion molecule-1; VCAM-1, vascular cell adhesion molecule-1; VEGF, vascular endothelial growth factor; PDGF, platelet-derived growth factor; TIMP-1, tissue inhibitor of metalloproteinase-1; TIMP-2, tissue inhibitor of metalloproteinase-2; MMP-9, metalloproteinase-9. 
and (4) regulatory effects on salt and water absorption at medullary collecting ducts $(52,53)$.

Another important renoprotective mechanism of PPAR $\gamma$ agonists is related to the inflammatory process. PPAR $\gamma$ stimulation seems to inhibit inflammatory cytokine production by macrophages $(54,55)$. Pioglitazone has been shown to diminish the oxidative stress at kidney level in diabetic rats and rabbits (56-59). Furthermore, it reduced TGF-beta1-induced fibronectin expression in mouse glomerular mesangial cells by inhibiting activator protein-1 (AP-1) $(56,58,60)$. In a murine sepsis model, a reduction in renal injury and dysfunction has also been reported in association with the anti-inflammatory effects of glitazones (61).

Pioglitazone inhibited cell growth and reduced matrix production in human kidney fibroblasts through mechanisms that included a reduction in the secretion of type IV collagen and fibronectin, a decrease in proline incorporation and a reduction of the activity of tissue inhibitor of metalloproteinase-1 (TIMP-1), TIMP-2, and metalloproteinase-9 (MMP-9) $(62,63)$. Other reported beneficial effects of PPAR $\gamma$ agonists include (i) antinephritic effects, by suppressing the recruitment of inflammatory cells; (ii) antiproliferative effects, by inhibiting mesangial proliferation induced by vascular endothelial growth factor (VEGF) and platelet-derived growth factor (PDGF); and (iii) mechanic effects, by attenuating mesangial contractile dysfunction (64-69).

Finally, glitazones reduced UAE in obese and diabetic rats $(36,70,71-73)$ and in type 2 diabetic patients (74). Although this glitazone-induced reduction in UAE is a consequence more than a cause, of the renoprotective effect of the drugs, it might contribute to the long-term beneficial effects reported in patients with renal disease.

\section{Diabetic nephropathy}

PPAR $\gamma$ agonists seem to have favourable effects on the development and/or progression of diabetic nephropathy. Exact mechanisms are not completely understood, although they might be related to haemodynamic changes or to the insulin-sensitising effect (Table 3).

Yoshimoto et al. (1997) demonstrated that therapy with pioglitazone not only improved lipid and glucose metabolism, but also lowered blood pressure, decreased proteinuria, and prevented glomerular injury, renal arteriolosclerosis and aortic medial wall thickening in genetically obese diabetic rats (35). Pioglitazone also improved the urinary albumin/creatinine ratio (ACR) and the glomerular and Bowman's capsule volume ratios, and reduced endothelial constitutive nitric oxide synthetase (ecNOS) in the endothelium of glomerular vessels in early stage of type 2 diabetic nephropathy in mice (75). An increase in renal tubular cell albumin uptake induced by pioglitazone has also been reported (76). The urinary albumin excretion rate (AER) was
Table 3 Actions of glitazones potentially protecting against the progression of diabetic nephropathy.

Reduction of blood pressure

Decrease of UAE

Improvement of urinary ACR and glomerular and Bowman's capsule volume ratio

Reduction of ecNOS in the endothelium of glomerular vessel Increase in renal tubular cell albumin uptake

Reduction of glomerular size and glomerular hyperfiltration

Diminution of production of extracellular matrix in glomeruli Improved of endothelial dysfunction

Protective role on podocytes decreasing urinary podocyte excretion

Improvement of insulin sensitivity

Abbreviations: UAE, urinary albumin excretion; ACR, albumin/creatinine ratio; ecNOS, endothelial constitutive nitric oxide synthetase.

significantly decreased after 12 weeks of treatment with thiazolidinediones, and there was a suppression of the loss of anionic sites of glomerular basement membranes (GBM) in streptozotocin-induced diabetic spontaneous hypertensive rats (73). Other authors have demonstrated that glitazones not only reduce, but also prevent, glomerular hyperfiltration, AER, and excessive production of extracellular matrix in glomeruli in streptozotocin-induced diabetic rats (72).

Preliminary results in human studies have been promising. Therapy with pioglitazone, $30 \mathrm{mg} /$ day, was accompanied by a significant reduction in UAE in 15 normotensive type 2 diabetic patients with microalbuminuria by about $40 \%$ and $69 \%$ at 6 and 12 months of therapy, respectively. At 12 months, UAE was also significantly lower in pioglitazone-treated patients in comparison with those treated with glibenclamide and voglibose (77). More recently, Agarwal et al. (78) reported the result of a randomised, open-label, study comparing glipizide with pioglitazone over 16 weeks in 44 type 2 diabetic patients with overt diabetic nephropathy. Glipizide produced a mean increase in proteinuria of $6.1 \%$, whereas pioglitazone therapy was followed by a proteinuria reduction of $7.2 \%$. This difference, however, was not statistically significant (78).

Similar findings have been reported with rosiglitazone. Treatment with rosiglitazone, $4 \mathrm{mg}$ b.i.d. for 52 weeks, was accompanied by a significant reduction $(\sim 25 \%)$ of microalbuminuria in a group of type 2 diabetic patients. This effect was not observed in those patients treated with glyburide. A greater proportion of patients treated with rosiglitazone achieved normoalbuminuria (ACR $<30 \mu \mathrm{g} / \mathrm{mg}$ ) than did patients treated with glyburide (43\% vs 6\%). Conversely, fewer patients in the rosiglitazone group developed microalbuminuria than in the glyburide group (11\% vs $7 \%$ ). Reduction in ACR did not strongly correlate with changes in fasting plasma glucose and HbAlc, but showed strong correlation with changes in mean 24-h systolic and diastolic blood pressure (79).

The first human study evaluating the effects of rosiglitazone on haemodynamic changes and endothelial 
function at renal level has been recently reported (80). Therapy with rosiglitazone improved glomerular hyperfiltration, renal endothelial dysfunction, and microalbuminuria of incipient diabetic nephropathy in type 2 diabetic patients. Rosiglitazone therapy was followed by a reduction of $60 \%$ in albuminuria. In these patients a positive correlation between the reductions of UAE and GFR was also found (80). Another study showed that the addition of rosiglitazone to glyburide produced a significant reduction of UAE $(\sim 38 \%)$ in patients with type 2 diabetes and hypertension (44). This effect was negatively correlated with changes in insulin sensitivity and positively with changes in systolic and diastolic blood pressure (44). More recently it has been reported that combined therapy with rosiglitazone and metformin was followed by a reduction of microalbuminuria significantly higher than that found with the combination of glyburide and metformin $(22.8 \%$ vs $7.1 \%$, $\mathrm{p}<0.001)$ in a group of subjects with microalbuminuria and type 2 diabetes. Moreover, rosiglitazone and metformin therapy was accompanied by a significant reduction in both systolic and diastolic 24-h ambulatory blood pressure (81).

Different mechanisms should be considered for the favourable effects of PPAR $\gamma$ agonists on diabetic nephropathy: (i) reduction of glomerular size and, therefore, glomerular hyperfiltration, in early phases of the diabetic nephropathy development, in association with an increment in the albumin uptake in renal tubular cells, probably through inhibition of DAG-PKC-ERK pathway $(71,72)$; (ii) improvement of endothelial dysfunction related to an increase in NO bioavailability which reduces intraglomerular capillary pressure and filtration fraction (80); (iii) protective role on podocytes in the initial phases of diabetic nephropathy (82); and (iv) improvement of insulin sensitivity (74) and blood pressure reduction $(74,79,81)$.

Long-term studies performed in a higher number of patients are needed to confirm these results and to consider these drugs as a part of the initial management of diabetic nephropathy.

\section{Chronic renal insufficiency}

PPAR $\gamma$ agonists are one of few therapeutic options for treatment of patients with type 2 diabetes and CRF with oral agents. Only few studies performed in this population have been reported up to date. Thiazolidinediones seem to be interesting because they might contribute to reduce the uraemia-associated insulin resistance. Moreover, agonists would maintain their efficacy on glycaemic control regardless of the presence or absence of CRF. Agrawal et al. (83) studied the effects of the addition of rosiglitazone to a SU (glyburide, gliclazide and glipizide) treatment regimen for 6 months, in patients with type 2 diabetes mellitus with mild to moderate renal impairment inadequately controlled by SU monotherapy. Results showed similar efficacy in patients with normal renal function, and in patients with mild to moderate renal impairment (83).

\section{Dialysis patients}

Therapy with PPAR $\gamma$ agonists has been recently evaluated in uraemic patients undergoing dialysis in combination with both oral antidiabetic agents and insulin (Table 4).

In a randomised, placebo-controlled study, pioglitazone significantly reduced $\mathrm{HbA1c}$ levels approximately by $0.6 \%$ in comparison with placebo in a group of 20 HD patients with type 2 diabetes. In addition, pioglitazone significantly reduced triglyceride and increased HDL-cholesterol levels (84). A retrospective study evaluated the clinical efficacy and safety profile of two glitazones in $\mathrm{HD}$ patients with type 2 diabetes (85). Forty patients were treated either with rosiglitazone or pioglitazone for 3 months associated to their habitual treatment (oral agents or insulin). The addition of a glitazone produced a reduction in HbA1c levels of about $0.6 \%$, without differences between both drugs. Moreover, a significant reduction in both systolic $(\sim 6.0 \mathrm{mmHg})$ and diastolic $(\sim 3.2 \mathrm{mmHg})$ blood pressures was also reported.

Insulin resistance, a risk factor for cardiovascular disease, is present in both diabetic and non diabetic uraemic patients on continuous ambulatory peritoneal dialysis (CAPD) (86-88). PPAR $\gamma$ agonists have shown to be effective in the reduction of insulin resistance in these patients. Rosiglitazone therapy, $4 \mathrm{mg}$ /day for 12 weeks in 15 non diabetic CAPD patients, was accompanied by a reduction in both insulin resistance, estimated by the homeostasis model assessment method (HOMA-IR), and the area under the curve of glucose and insulin after an oral glucose tolerance test (OGTT) with an improvement in insulin sensitivity index (ISI) (89). In an open-label randomised study performed in 52 insulin-treated patients with type 2 diabetes on CAPD therapy and stable glycaemic control, the addition of rosiglitazone ( $4 \mathrm{mg} /$ day) improved insulin sensitivity and decreased inflammatory response (90).

Table 4 Favourable effects reported of PPAR $\gamma$ agonists in CRF patients.

Similar efficacy on glycaemic control in combination with SU that patients with normal renal function

Reduction of $\mathrm{HbA} 1 \mathrm{c} \sim 0.6 \%$ with combined therapy in type 2 diabetic patients on $\mathrm{HD}$

Reduction of systolic and diastolic blood pressures in type 2 diabetic patients on HD

Diminution of insulin resistance in non diabetic uraemic patients on CAPD

Reduction of exogenous insulin needs in diabetic patients on CAPD

Diminution of serum levels of CRP in diabetic patients on CAPD 


\section{Renal transplantation}

Post-transplant diabetes mellitus (PTDM) is associated with reduced graft and patient survival in renal transplant recipients $(91,92)$. Insulin resistance contributes to the development of PTDM, therefore the effects of insulin sensitisers might be potentially beneficial in patients with post-transplant glucose intolerance or diabetes (93). A protective effect on cyclosporine-induced pancreatic and renal injury has been reported in rats treated with rosiglitazone (94). Beneficial effects of rosiglitazone have also been reported in humans $(95,96)$. Rosiglitazone therapy was followed by an increase in insulin sensitivity, a reduction in fasting and 2 hours plasma glucose and an improvement of endothelial function in renal transplant recipients with glucose intolerance (95). More recently, It has been reported that rosiglitazone adequately controlled mean fasting blood glucose in 16 of 22 patients with PTDM (96).

\section{Tolerance and safety profile of PPAR $\gamma$ agonists in CRF}

The main concerning adverse effects of PPAR $\gamma$ agonists in the treatment of type 2 diabetic patients with CRF are weight gain, oedema, and congestive heart failure (CHF) $(5,6,97)$. The mechanism involved is water retention which is due to activation of PPAR $\gamma$ pathway at the collecting duct, increasing sodium and water transport $(47,52,53)$. Weight gain is also influenced by an increase in subcutaneous fat stores at the expense of newly formed insulin-sensitive adypocytes (98). Oedema appears in approximately $3-5 \%$ of patients treated with PPAR $\gamma$ agonists. Both oedema and weight gain are more prevalent when using PPAR $\gamma$ agonists in combination with insulin. CHF rarely develops in patients treated with PPAR $y$ agonists in monotherapy, although the frequency of this complication increases when combined with insulin. CHF symptoms usually improve after the administration of diuretics and discontinuation of glitazone therapy (99). The potential for developing worsening CHF has propitiated that glitazones therapy has been considered a contraindication in patients with class 3 and 4 New York Heart Association (NYHA) heart failure (97). In patients with pre-existing nephropathy the combined therapy with glitazones and fibrates should be monitored by frequent measurements of serum creatine kinase and creatinine because of the risk of acute myopathy (100).

Because of these adverse effects some authors do not recommend treatment with PPAR $\gamma$ agonists in CRF patients (99). However, recent studies have shown that tolerance and safety profile of PPAR $\gamma$ agonists are appropriate in these patients. Pioglitazone was safe and well tolerated in a group of patients with several degrees of renal insufficiency and comparable to that observed in subjects with normal renal function (29). Therapy with rosiglitazone, $8 \mathrm{mg} /$ day, was not accompanied by severe adverse events in a group of 57 patients with mild, moderate and severe renal insufficiency (27). In patients with advanced diabetic nephropathy, pioglitazone therapy produced a similar number of serious adverse events in comparison with those observed in patients treated with glipizide (78). Finally, combined therapy with rosiglitazone and SU was well tolerated in a group of 301 type 2 diabetic patients with mild to moderate CRF inadequately controlled with monotherapy (83).

PPAR $\gamma$ agonists therapy in dialysis (HD and CAPD) patients has shown adequate safety and tolerance profiles. In the study of Manley (85), there were 3 hospitalisations for new or worsening CHF (2 patients on rosiglitazone and one on pioglitazone) in a group of $40 \mathrm{HD}$ patients with type 2 diabetes treated with glitazones. Interdialytic weight gain significantly increased $\sim 0.3 \mathrm{~kg}$ in rosiglitazone treated patients (85). Rosiglitazone therapy has been well tolerated in both diabetic and non diabetic uraemic patients on CAPD. Oedema in lower extremities and weight gain in approximately $2 \%$ of the patients have been reported $(89,90)$.

Altogether, these results suggest that PPAR $\gamma$ agonists might be an adequate alternative in the antihyperglycaemic therapy of diabetic patients with CRF, regardless of the treatment used for renal failure. According to the American Heart Association and the American Diabetes Association recommendations, in patients without clinical data of CHF but with one or more risk factors for its development, as it is the case in CRF patients, therapy with glitazones should be initiated at low doses, i.e, rosiglitazone $4 \mathrm{mg} /$ day and pioglitazone $15 \mathrm{mg} /$ day. The increases in dose should be gradual, with tight monitoring for signs of excessive weight gain, peripheral oedema, and/or CHF (97).

\section{Conclusions}

Although therapeutic possibilities with oral agents in type 2 diabetes mellitus are increasing, the presence of CRF is an important limitation for using the majority of the currently available oral antidiabetic drugs. In recent years several promising drugs have been introduced in the therapeutical armamentarium of these patients. PPAR $\gamma$ agonists are drugs essentially metabolised in the liver that have proven to exert beneficial effects in the kidney and in different conditions such as diabetic nephropathy and uraemia-associated insulin resistance. The few studies performed so far with PPAR $\gamma$ agonists in diabetic patients with CRF have shown favourable effects on several aspects of renal function without severe adverse effects. Moreover, the anti-inflammatory, haemodynamic, vascular and metabolic effects of these drugs and their potential benefits in other pathological conditions are also to be taken 
into account. Further studies are needed to clarify and clearly establish the therapeutic role of these agents in patients with renal diseases.

\section{References}

1 Centers for Disease Control and Prevention (CDC), Incidence of end-stage renal disease among persons with diabetes-United States, 1990-2002. MMWR Morbidity and Mortality Weekly Report 2005 1097-1100.

2 The Diabetes Control and Complications Trial Research Group, The effect of intensive treatment of diabetes on the development and progression of long-term complications in insulin-dependent diabetes mellitus. New England Journal of Medicine 1993329 977-986.

3 Stratton IM, Adler AI, Neil AW \& UK Prospective Diabetes Study Group. Association of glycaemia with macrovascular and microvascular complications of type 2 diabetes (UKPDS 35): Prospective observational study. British Medical Journal $2000 \mathbf{3 2 1}$ 405-412.

4 UK Prospective Diabetes Study (UKPDS) Group, Intensive bloodglucose control with sulphonylureas or insulin compared with conventional treatment and risk of complications in patients with type 2 diabetes (UKPDS 33). Lancet 1998352 837-853.

5 Inzucchi SE. Oral antihyperglycemic therapy for type 2 diabetes. Journal of American Medical Association 2002287 360-372.

6 Krentz AJ \& Bailey CJ. Oral antidiabetic agents. Drugs 200565 $385-411$.

7 Hollander PA, Levy P, Fineman MS, Maggs DG, Shen LZ, Strobel SA, Weyer C \& Kolterman OR. Pramlintide as an adjunct to insulin therapy improves long-term glycemic and weight control in patients with type 2 diabetes. Diabetes Care 200326 $784-790$.

8 Deacon CF \& Holst JJ. Dipeptidyl peptidase IV inhibitors: A promising new therapeutic approach for the management of type 2 diabetes. International Journal of Biochemistry \& Cell Biology 200538 831-844.

9 Bailey CJ. Drugs on the horizon for diabesity. Current Diabetes Reports 20055 353-359.

10 Yale JF. Oral antihyperglycemic agents and renal disease: new agents, new concepts. Journal of American Society of Nephrology 200516 S7-S10.

11 Yki-Järvinen H. Thiazolidinediones. New England Journal of Medicine 2004351 1106-1118.

12 Staels B \& Fruchart J. Therapeutic roles of peroxisome proliferator-activated receptor agonists. Diabetes 200554 2460-2470.

13 Guan Y \& Breyer MD. Peroxisome proliferator-activated receptors (PPARs): novel therapeutic targets in renal disease. Kidney International $20016014-30$.

14 Issemann I \& Green S. Activation of a member of the steroid hormone receptor superfamily by peroxisome proliferators. Nature $1990347645-650$.

15 Dreyer C, Krey G, Keller H, Givel F, Helftenbein G \& Wahli W. Control of the peroxisomal beta-oxidation pathway by a novel family of nuclear hormone receptors. Cell $19926 \mathbf{6 8} 879-887$.

16 Saad MF, Greco S, Osei K, Lewin AJ, Edwards CH, Nunez M \& Reinhardt RR. Ragaglitazar improves glycemic control and lipid profile in type 2 diabetic subjects. Diabetes Care 200427 1324-1329.

17 Buse JB, Rubin CJ, Frederich R, Viraswami-Appanna K, Lin KCH, Montoro R, Shockey G \& Davidson JA. Muraglitazar, a dual $(\alpha / \gamma)$ PPAR activator: a randomized, double-blind, placebo-controlled, 24-week monotherapy trial in adult patients with type 2 diabetes. Clinical Therapeutics 200527 1181-1195.

18 Nissen SE, Wolski K \& Topol EJ. Effect of muraglitazar on death and major adverse cardiovascular events in patients with type 2 diabetes mellitus. Journal of American Medical Association $20052942581-2586$.
19 Willson TM, Lambert MH \& Kliewer SA. Peroxisome proliferatoractivated receptor gamma and metabolic disease. Annual Review of Biochemistry 200170 341-367.

20 Chinetti G, Fruchart JC \& Staels B. Peroxisome proliferator-activated receptors (PPARs): nuclear receptors at the crossroads between lipid metabolism and inflammation. Inflammation Research $200049497-505$.

21 Phillips LS, Grunberger G, Miller E, Patwardhan R, Rappaport EB, Salzman A \& Rosiglitazone Clinical Trials Study Group, Onceand twice-daily dosing with rosiglitazone improves glycemic control in patients with type 2 diabetes. Diabetes Care 200124 308-315.

22 Pavo I, Jermendy G, Varkonyi TT, Kerenyi Z, Gyimesi A, Shoustov S, Shestakova M, Herz M, Johns D, Schluchter BJ, Festa A \& Tan MH. Effect of pioglitazone compared with metformin on glycemic control and indicators of insulin sensitivity in recently diagnosed patients with type 2 diabetes. Journal of Clinical Endocrinology and Metabolism 200388 1637-1645.

23 Herz M, Johns D, Reviriego J, Grossman LD, Godin C, Duran S, Hawkins F, Lochnan H, Escobar-Jimenez F, Hardin PA, Konkoy CS \& Tan MH. A randomized, double-blind, placebocontrolled, clinical trial of the effects of pioglitazone on glycemic control and dyslipidemia in oral antihyperglycemic medicationnaive patients with type 2 diabetes mellitus. Clinical Therapeutics 200325 1074-1095.

24 Goldberg RB, Kendall DM, Deeg MA, Buse JB, Zagar AJ, Pinaire JA, Tan MH, Khan MA, Perez AT, Jacober SJ \& GLAI Study Investigators, A comparison of lipid and glycemic effects of pioglitazone and rosiglitazone in patients with type 2 diabetes and dyslipidemia. Diabetes Care 200528 1547-1554.

25 Dormandy JA, Charbonnel B, Eckland DJ, Erdmann E, MassiBenedetti M, Moules IK, Skene AM, Tan MH, Lefebvre PJ, Murray GD, Standl E, Wilcox RG, Wilhelmsen L, Betteridge J, Birkeland K, Golay A, Heine RJ, Koranyi L, Laakso M, Mokan M, Norkus A, Pirags V, Podar T, Scheen A, Scherbaum W, Schernthaner G, Schmitz O, Skrha J, Smith U, Taton J \& PROactive investigators, Secondary prevention of macrovascular events in patients with type 2 diabetes in the PROactive Study (PROspective pioglitAzone Clinical Trial In macroVascular Events): a randomised controlled trial. Lancet 2005366 1279-1289.

26 Snyder RW \& Berns JS. Use of insulin and oral hypoglycemic medications in patients with diabetes mellitus and advanced kidney disease. Seminars in Dialysis 200417 365-370.

27 Chapelsky MC, Thompson-Culkin K, Miller AK, Sack M, Blum R \& Freed MI. Pharmacokinetics of rosiglitazone in patients with varying degrees of renal insufficiency. Journal of Clinical Pharmacology $2003 \mathbf{4 3 2 5 2 - 2 5 9 .}$

28 Thompson-Culkin K, Zussman B, Miller AK \& Freed MI. Pharmacokinetics of rosiglitazone in patients with end-stage renal disease. Journal of International Medical Research 200230 391-399.

29 Budde K, Neumayer HH, Fritsche L, Sulowicz W, Stompor T \& Eckland D. The pharmacokinetics of pioglitazone in patients with impaired renal function. British Journal of Clinical Pharmacology $200355368-374$.

30 Guan Y, Zhang Y, Davis L \& Breyer MD. Expression of peroxisome proliferator-activated receptors in urinary tract of rabbits and humans. American Journal of Physiology $1997 \quad 273$ F1013-F1022.

31 Yang T, Michele DE, Park J, Smart AM, Lin Z, Brosius FC 3rd, Schnermann JB \& Briggs JP. Expression of peroxisome proliferator-activated receptors and retinoid $\mathrm{X}$ receptors in the kidney. American Journal of Physiology 1999277 F966-F973.

32 Ishizuka T, Ito O, Tan L, Ogawa S, Kohzuki M, Omata K, Takeuchi K \& Ito S. Regulation of cytochrome P-450 4A activity by peroxisome proliferator-activated receptors in the rat kidney. Hypertension Research 200326 929-936. 
33 Izzedine H, Launay-Vacher V, Buhaescu I, Heurtier A Baumelou A \& Deray G. PPAR-gamma-agonists' renal effects. Minerva Urologica e Nefrologica 200557 247-260.

34 Dubey RK, Zhang HY, Reddy SR, Boegehold MA \& Kotchen TA. Pioglitazone attenuates hypertension and inhibits growth of renal arteriolar smooth muscle in rats. American Journal of Physiology. Regulatory, Integrative and Comparative Physiology 1993265 R726-R732.

35 Yoshimoto T, Naruse M, Nishikawa M, Naruse K, Tanabe A, Seki T, Imaki T, Demura R, Aikawa E \& Demura H. Anti-hypertensive and vasculo- and renoprotective effects of pioglitazone in genetically obese diabetic rats. American Journal of Physiology. Endocrinology and Metabolism 1997272 E989-E996.

36 Verma S, Bhanot S, Arakawa E, Yao L \& Mcneill JH. Direct vasodepressor effects of pioglitazone in spontaneously hypertensive rats. Pharmacology 199856 7-16.

37 Nishimoto Y, Tomida T, Matsui H, Ito T \& Okumura K. Decrease in renal medullary endothelial nitric oxide synthase of fructosefed, salt-sensitive hypertensive rats. Hypertension $2002 \mathbf{4 0}$ 190-194.

38 Khan O, Riazi S, Hu X, Song J, Wade JB \& Ecelbarger CA. Regulation of the renal thiazide-sensitive $\mathrm{Na}-\mathrm{Cl}$ cotransporter, blood pressure, and natriuresis in obese Zucker rats treated with rosiglitazone. American Journal of Physiology. Renal Physiology 2005 289 F442-F450.

39 Arima S, Kohagura K, Takeuchi K, Taniyama Y, Sugawara A, Ikeda Y, Abe M, Omata K \& Ito S. Biphasic vasodilatador action of troglitazone on the renal microcirculation. Journal of American Society of Nephrology $200213342-349$.

40 Inzucchi SE, Maggs DG, Spollett GR, Page SL, Rife FS, Walton V \& Shulman GI. Efficacy and metabolic effects of metformin and troglitazone in type II diabetes mellitus. New England Journal of Medicine 1998338 867-872.

41 Parulkar AA, Pendergrass ML, Granda-Ayala R, Lee TR \& Fonseca VA. Nonhypoglycemic effects of thiazolidinediones. Annals of Internal Medicine 2001 134 61-71.

42 Yosefy C, Magen E, Kiselevich A, Priluk R, London D, Volchek L \& Viskoper RJ Jr. Rosiglitazone improves, while Glibenclamide worsens blood pressure control in treated hypertensive diabetic and dyslipidemic subjects via modulation of insulin resistance and sympathetic activity. Journal of Cardiovascular Pharmacology $200444215-222$

43 Negro R, Mangieri T, Dazzi D, Pezzarossa A \& Hassan H. Rosiglitazone effects on blood pressure and metabolic parameters in nondipper diabetic patients. Diabetes Research and Clinical Practice $20057020-25$.

44 Sarafidis PA, Lasaridis AN, Nilsson PM, Mouslech TF, HitoglouMakedou AD, Stafylas PC, Kazakos KA, Yovos JG \& Tourkantonis AA. The effect of rosiglitazone on novel atherosclerotic risk factors in patients with type 2 diabetes mellitus and hypertension. An open-label observational study. Metabolism $2005541236-1242$

45 Negro R, Dazzi D, Hassan H \& Pezzarossa A. Pioglitazone reduces blood pressure in non-dipping diabetic patients. Minerva Endocrinologica $20042911-17$.

46 Wakino S, Hayashi K, Tatematsu S, Hasegawa K. Takamatsu I, Kanda T, Homma K, Yoshioka K, Sugano N \& Saruta T. Pioglitazone lowers systemic asymmetric dimethylarginine by inducing dimethylarginine dimethylaminohydrolase in rats. Hypertension Research 200528 255-262.

47 Gurnell M, Savage DB, Krishna V, Chatterjee K \& O’Rahilly S. The metabolic syndrome: peroxisome proliferator-activated receptor $\gamma$ and its therapeutic modulation. Journal of Clinical Endocrinology and Metabolism 200388 2412-2421.

48 Sung BH, Izzo JL Jr, Dandona P \& Wilson MF. Vasodilatory effects of troglitazone improve blood pressure at rest and during mental stress in type 2 diabetes mellitus. Hypertension $19993483-88$.

49 Marx N, Schonbeck U, Lazar MA, Libby P \& Plutzky J. Peroxisome proliferator-activated receptor gamma activators inhibit gene expression and migration in human vascular smooth muscle cells. Circulation Research 199883 1097-1103.

50 Marx N, Bourcier T, Sukhova GK, Libby P \& Plutzky J. PPARgamma activation in human endothelial cells increases plasminogen activator inhibitor type-1 expression: PPARgamma as a potential mediator in vascular disease. Arteriosclerosis, Thrombosis, and Vascular Biology $199919546-551$.

51 Walker AB, Naderali EK, Chattington PD, Buckingham RE \& Williams G. Differential vasoactive effects of the insulin sensitizers rosiglitazone (BRL 49653) and troglitazone on human small arteries in vitro. Diabetes $199847810-814$.

52 Song J, Knepper MA, Hu X, Verbalis JG \& Ecelbarger CA. Rosiglitazone activates renal sodium- and water-reabsorptive pathways and lowers blood pressure in normal rats. The Journal of Pharmacology and Experimental Therapeutics $2004 \mathbf{3 0 8}$ 426-433.

53 Zhang H, Zhang A, Kohan DE, Nelson RD, Gonzalez FJ \& Yang T. Collecting duct-specific deletion of peroxisome proliferator-activated receptor gamma blocks thiazolidinedione-induced fluid retention. Proceedings of the National Academy of Sciences of the United States of America 2005102 9406-9411.

54 Ricote M, Li AC, Willson TM, Kelly CJ \& Glass CK. The peroxisome proliferator- $\gamma$ activated receptor is a negative regulator of macrophage activation. Nature 1998391 79-82.

55 Jiang C, Ting AT \& Seed B. PPAR- $\gamma$ agonists inhibit production of monocyte inflammatory cytokines. Nature $199839182-86$.

56 Gumieniczek A. Effect of the new thiazolidinedione-pioglitazone on the development of oxidative stress in liver and kidney of diabetic rabbits. Life Science $200319553-562$.

57 Sivarajah A, Chatterjee PK, Patel NS, Todorovic Z, Hattori Y, Brown PA, Stewart KN, Mota-Filipe H, Cuzzocrea S \& Thiemermann C. Agonists of peroxisome-proliferator activated receptor-gamma reduce renal ischemia/reperfusion injury. American Journal of Nephrology 200323 267-276.

58 Guo B, Koya D, Isono M, Sugimoto T, Kashiwagi A \& Haneda M. Peroxisome proliferator-activated receptor-gamma ligands inhibit TGF-beta1-induced fibronectin expression in glomerular mesangial cells. Diabetes 200453 200-208.

59 Majithiya JB, Parmar AN, Trivedi CJ \& Balaraman R. Effect of pioglitazone on l-NAME induced hypertension in diabetic rats. Vascular Pharmacology 200543 260-266.

60 Maeda A, Horikoshi S, Gohda T, Tsuge T, Maeda K \& Tomino Y. Pioglitazone attenuates TGF-beta(1)-induction of fibronectin synthesis and its splicing variant in human mesangial cells via activation of peroxisome proliferator-activated receptor (PPAR)gamma. Cell Biology International $200529422-428$.

61 Lee S, Kim W, Kang KP, Moon SO, Sung MJ, Kim DH, Kim HJ \& Park SK. Agonist of peroxisome proliferator-activated receptorgamma, rosiglitazone, reduces renal injury and dysfunction in a murine sepsis model. Nephrology Dialysis Transplantation $2005201057-1065$.

62 Dong FQ, Li H, Cai WM, Tao J, Li O, Ruan Y, Zheng FP \& Zhang Z. Effects of pioglitazone on expressions of matrix metalloproteinases 2 and 9 in kidneys of diabetic rats. Chinese Medical Journal $20041171040-1044$

63 Zafiriou S, Stanners SR, Polhill TS, Poronnik P \& Pollock CA. Pioglitazone increases renal tubular cell albumin uptake but limits proinflammatory and fibrotic responses. Kidney International $2004651647-1653$.

64 Haraguchi K, Shimura H \& Onaya T. Suppression of experimental crescentic glomerulonephritis by peroxisome proliferator-activated receptor (PPAR)gamma activators. Clinical and Experimental Nephrology $2003727-32$.

65 Ghosh SS, Gehr TW, Ghosh S, Fakhry I, Sica DA, Lyall V \& Schoolwerth AC. PPARgamma ligand attenuates PDGF-induced mesangial cell proliferation: role of MAP kinase. Kidney International $2003 \mathbf{6 4} 52-62$.

66 Onozaki A, Midorikawa S, Sanada H, Hayashi Y, Baba T, Katoh T \& Watanabe T. Rapid change of glucose concentration promotes mesangial cell proliferation via VEGF: inhibitory effects of thiazo- 
lidinedione. Biochemical and Biophysical Research Communications $200431724-29$.

67 Xiong Z, Huang H, Li J, Guan Y \& Wang H. Anti-inflammatory effect of PPARgamma in cultured human mesangial cells. Renal Failure 200426 497-505.

68 Ueta M, Wakisaka M, Ago T, Kitazono T, Nakamura U, Yoshinari M, Iwase M \& Iida M. PPARgamma ligands attenuate mesangial contractile dysfunction in high glucose. Kidney International $200465961-971$.

69 Gruden G, Setti G, Hayward A, Sugden D, Duggan S, Burt D, Buckingham RE, Gnudi L \& Viberti G. Mechanical stretch induces monocyte chemoattractant activity via an NF-kappaBdependent monocyte chemoattractant protein-1-mediated pathway in human mesangial cells: inhibition by rosiglitazone. Journal of American Society Nephrology 200516 688-696.

70 Pershadsingh HA, Szollosi J, Benson S, Hyun WC, Feuerstein BG \& Kurtz TW. Effects of ciglitazone on blood pressure and intracellular calcium metabolism. Hypertension $1993 \mathbf{2 1}$ 1020-1023.

71 Isshiki K, Haneda M, Koya D, Maeda S, Sugimoto T \& Kikkawa R. Thiazolidinedione compounds ameliorate glomerular dysfunction independent of their insulin-sensitizing action in diabetic rats. Diabetes $2000 \mathbf{4 9} 1022-1032$.

72 Haneda M, Koya D \& Kikkawa R. Cellular mechanisms in the development and progression of diabetic nephropathy: activation of the DAG-PKC-ERK pathway. American Journal of Kidney Diseases 200138 (Suppl 1) S178-S181.

73 Yamashita H, Nagai Y, Takamura T, Nohara E \& Kobayashi K. Thiazolidinedione derivatives ameliorate albuminuria in streptozotocin-induced diabetic spontaneous hypertensive rat. Metabolism 200251 403-408.

74 Sarafidis PA, Lasaridis AN, Nilsson PM, Hitoglou-Makedou AD, Pagkalos EM, Yovos JG, Pliakos CI \& Tourkantonis AA. The effect of rosiglitazone on urine albumin excretion in patients with type 2 diabetes mellitus and hypertension. American Journal of Hypertension $2005 \mathbf{1 8} 227-234$.

75 Tanimoto M, Fan Q, Gohda T, Shike T, Makita Y \& Tomino Y. Effect of pioglitazone on the early stage of type 2 diabetic nephropathy in KK/Ta mice. Metabolism 2004 53 1473-1479.

76 Zafiriou S, Stanner SR, Saad S, Polhill TS, Poronnik P \& Pollock CA. Pioglitazone inhibits cell growth and reduces matrix production in human kidney fibroblasts. Journal of American Society of Nephrology $2005 \mathbf{1 6}$ 638-645.

77 Nakamura T, Matsuda T, Kawagoe Y, Ogawa H, Takahashi Y, Sekizuka K \& Koide H. Effect of pioglitazone on carotid intimamedia thickness and arterial stiffness in type 2 diabetic nephropathy patients. Metabolism 200453 1382-1386.

78 Agarwal R, Saha C, Battiwala M, Vasavada N, Curley T, Chase SD, Sachs N \& Semret MH. A pilot randomized controlled trial of renal protection with pioglitazone in diabetic nephropathy. Kidney International 200568 285-292.

79 Bakris G, Viberti G, Weston WM, Heise M, Porter LE \& Freed MI. Rosiglitazone reduces urinary albumin excretion in type II diabetes. Journal of Human Hypertension 2003 17 7-12.

80 Pistrosch F, Herbrig K, Kindel B, Passauer J, Fischer S \& Gross P. Rosiglitazone improves glomerular hyperfiltration, renal endothelial dysfunction, and microalbuminuria of incipient diabetic nephropathy in patients. Diabetes $2005 \mathbf{5 4} 2206-2211$.

81 Ruilope LM, Bakris GL, McMorn SO, Weston WM, Huang C, Heise MA, Porter LE \& Freed MI. Rosiglitazone added to metformin reduces urinary albumin/creatinine ratio and ambulatory blood pressure in subjects with microalbuminuria and type 2 diabetes. 41st Annual Meeting of The European Association for the Study of Diabetes. Athens. September 2005, p779 A283.

82 Nakamura T, Ushiyama C, Osada S, Hara M, Shimada N \& Koide H. Pioglitazone reduces urinary podocyte excretion in type 2 diabetes patients with microalbuminuria. Metabolism 200150 1193-1196.

83 Agrawal A, Sautter MC \& Jones NP. Effects of rosiglitazone maleate when added to a sulfonylurea regimen in patients with type
2 diabetes mellitus and mild to moderate renal impairment: a post hoc analysis. Clinical Therapy $2003252754-2764$.

84 Nakamura T, Ushiyama C, Osada S, Shimada N, Ebihara I \& Koide H. Effect of pioglitazone on dyslipidemia in hemodialysis patients with type 2 diabetes. Renal Failure 200123 863-864.

85 Manley HJ \& Allcock NM. Thiazolidinedione safety and efficacy in ambulatory patients receiving hemodialysis. Pharmacotherapy $200323861-865$.

86 Iglesias P, Grande C, Mendez J, Fernandez-Reyes MJ, Bajo MA, Selgas R \& Diez JJ. Serum insulin and insulin-like growth factor binding protein-1 levels in adult patients undergoing peritoneal dialysis. Advances in Peritoneal Dialysis 199612 71-76.

87 Cheng SC, Chu TS, Huang KY, Chen YM, Chang WK, Tsai TJ \& $\mathrm{Wu} \mathrm{KD}$. Association of hypertriglyceridemia and insulin resistance in uremic patients undergoing CAPD. Peritoneal Dialysis International 2001 21 282-289.

88 Tuzcu A, Bahceci M, Yilmaz ME, Turgut C \& Kara IH. The determination of insulin sensitivity in hemodialysis and continuous ambulatory peritoneal dialysis in nondiabetic patients with endstage renal disease. Saudi Medical Journal 200526 786-791.

89 Lin SH, Lin YF, Kuo SW, Hsu YJ \& Hung YJ. Rosiglitazone improves glucose metabolism in nondiabetic uremic patients on CAPD. American Journal of Kidney Diseases 200342 774-780.

90 Wong TY, Szeto CC, Chow KM, Leung CB, Lam CW \& Li PK. Rosiglitazone reduces insulin requirement and C-reactive protein levels in type 2 diabetic patients receiving peritoneal dialysis. American Journal of Kidney Diseases 200546 713-719.

91 Cosio FG, Pesavento TE, Kim S, Osei K, Henry M \& Ferguson RM. Patient survival after renal transplantation: IV. Impact of posttransplant diabetes. Kidney International 200262 1440-1446.

92 Gonzalez-Posada JM, Hernandez D, Bayes Genis B, Garcia Perez J \& Rivero Sanchez M. Impact of diabetes mellitus on kidney transplant recipients in Spain. Nephrology Dialysis Transplantation 200419 (Suppl 3) iii57-iii61.

93 Hjelmesaeth J, Hagen M, Hartmann A, Midtvedt K, Egeland T \& Jenssen T. The impact of impaired insulin release and insulin resistance on glucose intolerance after renal transplantation. Clinical Transplantation $200216389-396$.

94 Chung BH, Li C, Sun BK, Lim SW, Ahn KO, Yang JH, Choi YH, Yoon KH, Sugawara A, Ito S, Kim J \& Yang CW. Rosiglitazone protects against cyclosporine-induced pancreatic and renal injury in rats. American Journal of Transplantation 2005 5 1856-1867.

95 Voytovich MH, Simonsen C, Jenssen T, Hjelmesæth J, Åsberg A \& Hartmann A. Short-term treatment with rosiglitazone improves glucose tolerance, insulin sensitivity and endothelial function in renal transplant recipients. Nephrology Dialysis Transplantation 200520 413-418.

96 Pietruck F, Kribben A, Van TN, Patschan D, Herget-Rosenthal S, Janssen O, Mann K, Philipp T \& Witzke O. Rosiglitazone is a safe and effective treatment option of new-onset diabetes mellitus after renal transplantation. Transplantation International 2005 18 483-486.

97 A consensus statement from the American Heart Association and American Diabetes Association, Thiazolidinedione use, fluid retention, and congestive heart failure. Diabetes Care $200427256-263$.

98 Kelly IE, Han TS, Walsh K \& Lean ME. Effects of thiazolidinedione compound on body fat and fat distribution of patients with type 2 diabetes. Diabetes Care 199922 288-293.

99 Kermani A \& Garg A. Thiazolidinedione-associated congestive heart failure and pulmonary edema. Mayo Clinics Proceedings 200378 1088-1091.

100 Ledl M, Hohenecker J, Francesconi C, Roots I, Bauer MF \& Roden M. Acute myopathy in a type 2 diabetic patient on combination therapy with metformin, fenofibrate and rosiglitazone. Diabetologia 200548 1996-1998.

Received 6 December 2005

Accepted 7 February 2006 